\title{
The use of 3 sugammadex out of 5 reversal of during recovery of rocuronium-induced neuromuscular blockade in a patient with post-tonsillectomy hemorrhage
} -a case report-

\author{
Hee-Jong Lee ${ }^{1}$, Kyo Sang Kim ${ }^{1}$, Tae Yeon Kim ${ }^{1}$, Jeoung Hyuk Lee ${ }^{2}$, and Miae Jeong ${ }^{1}$ \\ Department of Anesthesiology and Pain Medicine, ${ }^{1}$ Hanyang University College of Medicine, Seoul, ${ }^{2}$ Dongguk University Ilsan \\ Hospital, Goyang, Korea
}

Post-tonsillectomy hemorrhage (PTH) is the most frequent complication of tonsillectomy, and occasionally results in a lethal outcome. A 21-year-old man (height $180 \mathrm{~cm}$, weight $95 \mathrm{~kg}$ ) was scheduled for a bilateral tonsillectomy and uvulopalatopharyngoplasty for treatment of obstructive sleep apnea. He required 5 rounds of general anesthesia due to recurrent PTH. The anesthesiologist used sugammadex a total of 3 times to achieve the successful reversal of the deep neuromuscular blockade (NMB) induced by rocuronium. After sugammadex $2 \mathrm{mg} / \mathrm{kg}$ was administered, the NMB was reversed in 2 minutes each time. Re-administration of rocuronium within a short time interval after sugammadex may result in unpredictable effects of neuromuscular blocking agents. Sugammadex made it possible to perform a rapid, complete reverse when the residual block was maintained by an incomplete reversal of anticholinesterase. (Korean J Anesthesiol 2014; 67: 43-47)

Key Words: Postoperative hemorrhage, Rocuronium, Sugammadex, Tonsillectomy.

Post-tonsillectomy hemorrhage (PTH) is the most frequent complication of tonsillectomy and may result in lethal outcomes, especially in during a primary $\mathrm{PTH}(<24 \mathrm{~h}$ postoperatively) [1]. A previous study reported a mortality rate of tonsillectomy of $1 / 16,381$, among which $1 / 44,429(0.002 \%)$ cases were attributed to anesthetic causes, $1 / 48,627(0.002 \%)$ cases to cardiac arrest, and $1 / 55,637(0.002 \%)$ cases to hemorrhage [2]. The incidence of PTH has been reported to range from 2.7 to $20 \%$ in all age groups [3]. Sugammadex, a modified $\gamma$-cyclodextrin, has proven to be highly effective for the reversal of moderate or deep neuromuscular blockade induced by rocuronium or vecuronium [4]. Rapid sequence intubation (RSI) with rocuronium followed by reversal with sugammadex allows for earlier re-establishment of spontaneous ventilation than when succinylcholine is used for

Received: June 20, 2013. Revised: July 12, 2013. Accepted: July 15, 2013.

Corresponding author: Kyo Sang Kim, M.D., Ph.D., Department of Anesthesiology and Pain Medicine, Hanyang University College of Medicine, 222, Wangsimni-ro, Seongdong-gu, Seoul 133-792, Korea. Tel: 82-2-2290-8680, Fax: 82-2-2299-8692, E-mail: kimks@hanyang.ac.kr (c) This is an open-access article distributed under the terms of the Creative Commons Attribution Non-Commercial License (http:// creativecommons.org/licenses/by-nc/3.0/), which permits unrestricted non-commercial use, distribution, and reproduction in any medium, provided the original work is properly cited. 
muscle relaxation [5]. Re-administration of $0.6 \mathrm{mg} / \mathrm{kg}$ rocuronium can be performed 6 hours after using sugammadex $2 \mathrm{mg} / \mathrm{kg}$, which is the recommended waiting time. However, it is possible to re-administer rocuronium $1.2 \mathrm{mg} / \mathrm{kg}$ after sugammadex 2 $\mathrm{mg} / \mathrm{kg}$ without waiting [6]. We report a case in which the patient presented with primary post-tonsillectomy hemorrhage and required 5 rounds of general anesthesia in addition to 3 separate doses of sugammadex for the reversal of a deep neuromuscular blockade (NMB) induced by rocuronium.

\section{Case Report}

A 21-year-old man (height $=180 \mathrm{~cm}$, weight $=95 \mathrm{~kg}$, body mass index $=29.3 \mathrm{~kg} / \mathrm{m}^{2}$ ) presented to the outpatient department with a long history of frequent and severe snoring. On physical exam, the patient exhibited bilateral tonsillar hypertrophy. After a diagnosis of obstructive sleep apnea was made, a bilateral tonsillectomy and uvulopalatopharyngoplasty was planned for treatment. Prior to surgery, the patient had normal laboratory results with hemoglobin $(\mathrm{Hb})$ of $15.8 \mathrm{~g} / \mathrm{dl}$ and no systemic or hematological diseases or history of bleeding disorders. On the day of the surgery, the patient received no premedication due to the history of sleep apnea. Intraoperative monitors included electrocardiogram, non-invasive blood pressure (BP), pulse oximetry $\left(\mathrm{SpO}_{2}\right)$, and end-tidal $\mathrm{CO}_{2}$. Pre-anesthetic vital signs were BP 120/82 mmHg, HR 68 bpm, and $\mathrm{SpO}_{2}$ 96\%. General anesthesia was induced with remifentanil $0.5 \mu \mathrm{g} / \mathrm{kg} / \mathrm{min}$ and propofol 180 mg IV at 10:10 AM. At loss of eyelash reflex, cisatracurium 16 mg was administered, and the trachea was intubated after a short period of facemask ventilation. Anesthesia was maintained with sevoflurane 2 vol\% in 50\% oxygen-enriched air and remifentanil $0.2 \mu \mathrm{g} / \mathrm{kg} / \mathrm{min}$. A complete time sequence of general anesthesia is shown in Table 1. The surgery was completed and uneventful. The neuromuscular block was antagonized with glycopyrrolate $0.6 \mathrm{mg}$ and pyridostigmine $15 \mathrm{mg}$ IV without neuromuscular monitoring upon the completion of the surgical procedure at 11:25 AM. Postoperatively, a physical examination confirmed the presence of acute bleeding in the left inferior pole of the tonsillectomy site in the post anesthetic care unit. The surgeon requested an emergent re-operation under general anesthesia for the control of bleeding.

A RSI for a second round of general anesthesia was performed with propofol $120 \mathrm{mg}$, midazolam $5 \mathrm{mg}$, and rocuronium 100 mg at 11:55 AM. We successfully performed an endotracheal intubation with Sellick's maneuver without difficulty. The surgeon confirmed active bleeding due to an aberrant arterial blood supply in the left inferior pole of the tonsillectomy site. After the completion of the surgical procedure, no twitch was shown after train-of-four $(\mathrm{TOF})$ stimulation $(\mathrm{TOF}=0)$ with Neuro-Stim ${ }^{\mathrm{TM}}$ (Model NS-3CC, Houston, TX, USA) at 12:40 PM. The neuromuscular block was then antagonized with sugammadex $200 \mathrm{mg}$ IV and the rocuronium-induced NMB was completely reversed within 2 min. Extubation was carried out after consciousness was regained and regular, spontaneous respirations resumed. The patient was transferred to the recovery room, and there were no specific findings on physical exam. A post-operative laboratory assessment showed $\mathrm{Hb}$ of $14.6 \mathrm{~g} / \mathrm{dl}$ (Table 1).

After $6 \mathrm{~h}$ and $20 \mathrm{~min}$, the surgeon again requested emergent

Table 1. Time Sequence of Repeated Anesthesia for Post-tonsillectomy Hemorrhage

\begin{tabular}{|c|c|c|c|c|}
\hline $\begin{array}{l}\text { Order \& } \\
\text { interval }\end{array}$ & Time & Anesthesia & $\begin{array}{l}\text { Hemoglobin } \\
(\mathrm{g} / \mathrm{dl})\end{array}$ & Matters \\
\hline 1st & $\begin{array}{l}10: 10 \\
11: 25\end{array}$ & $\begin{array}{l}\text { Propofol } 180 \mathrm{mg}+\text { cisatracurium } 16 \mathrm{mg} \\
\text { Glycopyrrolate } 0.6 \mathrm{mg}+\text { pyridostigmine } 15 \mathrm{mg}\end{array}$ & 15.8 & Elective operation \\
\hline $30 \mathrm{~min}$ & & & & $\begin{array}{l}\text { Surgeon requested an emergent bleeding control at post } \\
\text { anesthetic care unit. }\end{array}$ \\
\hline 2nd & $11: 55$ & $\begin{array}{l}\text { Propofol } 120 \mathrm{mg}+\text { midazolam } 5 \mathrm{mg}+ \\
\text { rocuronium } 100 \mathrm{mg}\end{array}$ & 14.6 & Rapid sequence induction \\
\hline $6 \mathrm{~h} 20 \mathrm{~min}$ & $12: 40$ & Sugammadex $200 \mathrm{mg}$ & & $\begin{array}{l}\mathrm{TOF}=0 \rightarrow \mathrm{TOF}=4 \\
\text { Surgeon requested another emergent bleeding control at the } \\
\text { ambulatory of Otolaryngology. }\end{array}$ \\
\hline $3 \mathrm{rd}$ & 19:00 & Propofol $120 \mathrm{mg}$ + rocuronium $40 \mathrm{mg}$ & 13.2 & \\
\hline $2 \mathrm{~h} 35 \mathrm{~min}$ & $20: 00$ & Sugammadex $200 \mathrm{mg}$ & & $\begin{array}{l}\text { TOF }=0 \rightarrow \mathrm{TOF}=4 \\
\text { Surgeon requested another emergent bleeding control at the } \\
\text { Otolaryngology ward. }\end{array}$ \\
\hline 4 th & $\begin{array}{r}22: 35 \\
0: 20\end{array}$ & $\begin{array}{l}\text { Propofol } 120 \mathrm{mg}+\text { rocuronium } 40 \mathrm{mg}+10 \mathrm{mg} \\
\text { Glycopyrrolate } 0.4 \mathrm{mg}+\text { pyridostigmine } 10 \mathrm{mg}\end{array}$ & 11.6 & $\mathrm{TOF}=1 \rightarrow \mathrm{TOF}=4$ \\
\hline $20 \mathrm{~min}$ & & & & $\begin{array}{l}\text { Blood vomiting after extubation (more than } 200 \mathrm{ml} \text { ) } \rightarrow \\
\text { Surgeon requested a re-induction for emergent bleeding control. }\end{array}$ \\
\hline 5 th & $\begin{array}{l}0: 40 \\
1: 30 \\
1: 45\end{array}$ & $\begin{array}{l}\text { Propofol } 120 \mathrm{mg}+\text { rocuronium } 100 \mathrm{mg} \\
\text { Glycopyrrolate } 0.4 \mathrm{mg} \text { + pyridostigmine } 10 \mathrm{mg} \\
\text { Sugammadex } 200 \mathrm{mg}\end{array}$ & & $\begin{array}{l}\text { Rapid sequence induction, transfusion } 1 \text { unit. } \\
\text { TOF }=1 \rightarrow \mathrm{TOF}=1 \\
\text { TOF }=1 \rightarrow \mathrm{TOF}=4 \text {, transfer to ICU. }\end{array}$ \\
\hline
\end{tabular}


anesthesia and re-operation for control of bleeding. The surgeon attempted to control bleeding at the ambulatory otolaryngology clinic but was unable to do so. When the patient arrived at the operating room $(\mathrm{OR})$, vital signs were within normal limits and $\mathrm{Hb}$ was found to be $13.2 \mathrm{~g} / \mathrm{dl}$. A third round of general anesthesia was induced with propofol $120 \mathrm{mg}$ and rocuronium 40 mg by the on-call resident at 19:00 PM. General anesthesia was uneventful. At the end of the surgical procedure, the neuromuscular block was antagonized with sugammadex $200 \mathrm{mg}$ IV and a TOF $=0$ at 20:00 PM. The rocuronium-induced NMB was again completely reversed in $2 \mathrm{~min}$. The patient was again extubated successfully and transferred to the recovery room with no specific findings (Table 1).

After $2 \mathrm{~h}$ and $35 \mathrm{~min}$, the surgeon requested another emergent operation due to excessive bleeding in the hospital ward. When the patient arrived at the OR, vital signs were stable and $\mathrm{Hb}$ was $11.6 \mathrm{~g} / \mathrm{dl}$. A fourth induction of general anesthesia was performed with propofol $120 \mathrm{mg}$ and rocuronium $40 \mathrm{mg}$ by the same resident at 22:35 PM. During TOF stimulation, 1 twitch was seen, and an additional dose of rocuronium $10 \mathrm{mg}$ was given due to bucking $20 \mathrm{~min}$ after the induction of anesthesia. At the end of the procedure, the neuromuscular block was antagonized with glycopyrrolate $0.4 \mathrm{mg}$ and pyridostigmine $10 \mathrm{mg}$ IV with a TOF $=1$ at the end of the surgical procedure at 0:20 AM. Extubation was carried out after confirming the recovery of consciousness, regular respiration, and the absence of fade on TOF monitoring. After extubation, the patient vomited a large amount of blood on the operating table (approximated to be more than $200 \mathrm{ml}$ ). However, the patient was alert and aware of his surroundings and had regular respirations (Table 1).

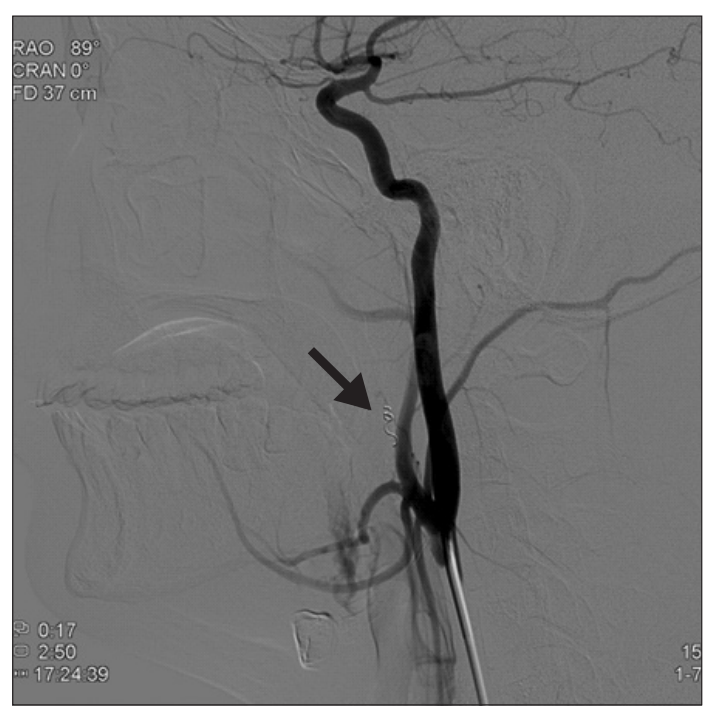

Fig. 1. Selective angiography of the left external carotid artery after complete embolization of the ascending pharyngeal artery with polyvinyl alcohol particle and Tornado coil.
After $20 \mathrm{~min}$, the surgeon requested a re-induction of general anesthesia for additional bleeding control. An RSI for a fifth round of general anesthesia was performed with propofol 120 $\mathrm{mg}$ and rocuronium $100 \mathrm{mg}$ at 0:40 AM. We successfully performed an endotracheal intubation immediately with Sellick's maneuver. The patient was transfused with 1 unit of packed red blood cells. The neuromuscular block was antagonized with glycopyrrolate $0.4 \mathrm{mg}$ and pyridostigmine $10 \mathrm{mg}$ IV with a TOF $=1$ after the surgical procedure was completed at 1:30 AM. Approximately 15 min passed after the NMB was antagonized as above, but no evidence of recovery from the rocuroniuminduced NMB was seen. Therefore, we injected a bolus of IV sugammadex $200 \mathrm{mg}$ to reverse the residual NMB. Once again, the NMB was completely reversed within $2 \mathrm{~min}$, and tracheal extubation was performed in the OR uneventfully (Table 1). The patient was then transferred to the intensive care unit. A decision by surgeon was made to perform angiography of the left external carotid artery with subsequent embolization of the bleeding vessel. Embolization of the left ascending pharyngeal artery was performed with polyvinyl alcohol particle $(350 \mu \mathrm{m})$ and Tornado Embolization Microcoil (Cook, Bloomington, USA) (3/2 mm) (Fig. 1). The patient's postoperative course was uneventful, and $\mathrm{Hb}$ was found to be $10.5 \mathrm{~g} / \mathrm{dl}$. After a 5-day hospital course, the patient was discharged without further complications.

\section{Discussion}

Life-threatening post-tonsillectomy bleeding requires an aggressive approach with surgical management. PTH occurs in approximately 1 in 20 adults (5.1\%), and more than half of patients who bleed are likely to require a procedure of some type to control their hemorrhage [7]. Aberrant arterial blood supply to the tonsillar region derived from the internal carotid artery or the carotid bulb may be present. To control bleeding, electrocauterization, packing of the pharynx, or angiographic embolization of the feeding artery may become necessary [8]. The endovascular embolization due to refractory bleeding after tonsillectomy proved to be a valuable treatment method as an effective alternative to surgical intervention. It is a safe and permanent treatment option in this potentially life-threatening complication [9]. In a case such as this, the aberrant arterial blood supply in the left inferior pole of tonsillectomy site caused continuous bleeding. The anesthesiologist has experienced difficulties, because an experienced surgeon has embarrassed due to repetitive bleeding.

In the first induction of anesthesia, no problems were encountered with conventional anesthesia, although neuromuscular monitoring was not performed. The most common anesthetic used for RSI during the management of children with PTH is succinylcholine [10]. Since the introduction of sugammadex, 
RSI with rocuronium followed by reversal with sugammadex allowed for earlier establishment of spontaneous ventilation than with succinylcholine, which has many adverse side events [5]. During the second round of anesthesia, rocuronium $100 \mathrm{mg}$ (1 $\mathrm{mg} / \mathrm{kg}$ ) was injected for RSI, followed by reversal with sugammadex $200 \mathrm{mg}(2 \mathrm{mg} / \mathrm{kg})$ at deep NMB (TOF =0). During the operation, NMB monitoring was difficult due to problems attaching leads to the arms during the operation. TOF stimulation was applied at the ulnar nerve using conventional instrumental monitoring rather than quantitative monitoring due to convenience. Deep NMB was maintained for bleeding control in an attempt to not disturb the procedure. During NMB reversal, we found an absence of fade on TOF monitoring just 2 min after sugammadex was administered.

Re-administration of $0.6 \mathrm{mg} / \mathrm{kg}$ rocuronium could then be given after sugammadex at the recommended waiting time of $6 \mathrm{~h}$ [6]. During the third anesthesia induction, the patient condition was not critical. An on-call resident used rocuronium $40 \mathrm{mg}$ for muscle relaxation during intubation followed by reversal with sugammadex $200 \mathrm{mg}$ at deep NMB $(\mathrm{TOF}=0)$. An absence of fade on TOF monitoring was shown 2 min after sugammadex was given.

For the fourth round of anesthesia, the same resident used rocuronium $40 \mathrm{mg}$ for intubation $2 \mathrm{~h}$ and $35 \mathrm{~min}$ after the previous NMB reversal with sugammadex. However, we believe this decision was made without considering the recent sugammadex use. When rocuronium is used within a short time interval (less than $6 \mathrm{~h}$ ) after sugammadex administration, the onset time of rocuronium may be prolonged and may also have an unpredictable duration of action [6]. We suspect that the additional dose of rocuronium $10 \mathrm{mg}$ due to bucking may be related to the short time interval between sugammadex and rocuronium administration. In situations such as these, the benzylisoquinoline class of medications are recommended instead of re-administering rocuronium within $6 \mathrm{~h}$ after sugammadex [11]. When considering this case, cisatracurium for muscle relaxation and intubation may have been a better choice for the fourth round anesthesia. However, one drawback of cisatracurium is the slower onset time than rocuronium [12]. Reversal of the rocuroniuminduced NMB with pyridostigmine at a moderate NMB (TOF = 1) was uneventful. After extubation, the patient vomited more than $200 \mathrm{ml}$ of blood on the operating table; however, he was alert and showed regular respirations. Postoperative nausea and vomiting (PONV) after an operation for PTH is common due to blood swallowed during the procedure. Therefore, patient awareness and complete reflexes are important, but aspiration must be avoided and monitored closely during the recovery period. However, PONV increases the risk of primary hemorrhage and unexpected postoperative hospital admissions [13]. In this case the patient did not aspirate, but did have an increased risk of PTH due to PONV.

For the fifth round of anesthesia, rocuronium $100 \mathrm{mg}$ (1 mg/ $\mathrm{kg}$ ) was injected for RSI after a time interval from sugammadex administration of $4 \mathrm{~h}$ and $40 \mathrm{~min}$. It has been reported that readministration of $1.2 \mathrm{mg} / \mathrm{kg}$ rocuronium could have been given after sugammadex $2 \mathrm{mg} / \mathrm{kg}$ without a waiting time [6]. The neuromuscular block was antagonized with pyridostigmine $10 \mathrm{mg}$ and $\mathrm{a}$ TOF $=1$. However, neuromuscular monitoring did not show the expected recovery, and the patient had residual paralysis after $15 \mathrm{~min}$. It has been shown previously that the reversal of NMB with anticholinesterase drugs may not be complete after a large dose of a neuromuscular blocking agent [14]. Sugammadex resolved the residual $\mathrm{NMB}$ within $2 \mathrm{~min}$, even after reversal with anticholinesterase agents, and is a safe alternative to reversal of NMB induced by steroidal non-depolarizing agents [15]. In this case, deep rocuronium-induced NMB can be reversed successfully with sugammadex at doses of $2 \mathrm{mg} / \mathrm{kg}$ and in as little as $2 \mathrm{~min}$. Re-administration of rocuronium within a short time interval after sugammadex may result in unpredictable effects of the NMB agent [6]. Sugammadex made it possible to perform a rapid, complete reverse when the residual block was maintained by an incomplete reversal of anticholinesterase.

\section{References}

1. Windfuhr JP, Schloendorff G, Baburi D, Kremer B. Lethal outcome of post-tonsillectomy hemorrhage. Eur Arch Otorhinolaryngol 2008; 265: 1527-34.

2. Pratt LW. Tonsillectomy and adenoidectomy: mortality and morbidity. Trans Am Acad Ophthalmol Otolaryngol 1970; 74: 1146-54.

3. Windfuhr JP, Ulbrich T. Post-tonsillectomy hemorrhage: results of a 3-month follow-up. Ear Nose Throat J 2001; 80: 790, 795-8.

4. Mirakhur RK. Sugammadex in clinical practice. Anaesthesia 2009; 64 Suppl 1: 45-54.

5. Sørensen MK, Bretlau C, Gätke MR, Sørensen AM, Rasmussen LS. Rapid sequence induction and intubation with rocuroniumsugammadex compared with succinylcholine: a randomized trial. Br J Anaesth 2012; 108: 682-9.

6. Cammu G, de Kam PJ, De Graeve K, van den Heuvel M, Suy K, Morias K, et al. Repeat dosing of rocuronium 1.2 mg kg-1 after reversal of neuromuscular block by sugammadex $4.0 \mathrm{mg} \mathrm{kg-1}$ in anaesthetized healthy volunteers: a modelling-based pilot study. Br J Anaesth 2010; 105: 487-92.

7. Bhattacharyya N. Evaluation of post-tonsillectomy bleeding in the adult population. Ear Nose Throat J 2001; 80: 544-9. 
8. McIntosh DL, Douglas G, Lee K, Allen J, Mahadevan M. External carotid artery blood supply to the orbit. Int J Pediatr Otorhinolaryngol 2007; 71: 1623-6.

9. Windfuhr JP. Indications for interventional arteriography in post-tonsillectomy hemorrhage. J Otolaryngol 2002; 31: 18-22.

10. Fields RG, Gencorelli FJ, Litman RS. Anesthetic management of the pediatric bleeding tonsil. Paediatr Anaesth 2010; 20: 982-6.

11. Epemolu O, Bom A, Hope F, Mason R. Reversal of neuromuscular blockade and simultaneous increase in plasma rocuronium concentration after the intravenous infusion of the novel reversal agent Org 25969. Anesthesiology 2003; 99: 632-7.

12. Lee H, Jeong S, Choi C, Jeong H, Lee S, Jeong S. Anesthesiologist's satisfaction using between cisatracurium and rocuronium for the intubation in the anesthesia induced by remifentanil and propofol. Korean J Anesthesiol 2013; 64: 34-9.

13. Lee C, Kim TY, Song YK, Son Y, Cheong YK, Kim MS. The effect of preoperative dexamethasone on profopol injection pain, postoperative nausea and vomiting undergoing otolaryngology-head and neck surgery. Korean J Anesthesiol 2006; 50: 490-4.

14. Kim KS, Lew SH, Cho HY, Cheong MA. Residual paralysis induced by either vecuronium or rocuronium after reversal with pyridostigmine. Anesth Analg 2002; 95: 1656-60.

15. de Menezes CC, Peceguini LA, Silva ED, Simões CM. Use of sugammadex after neostigmine incomplete reversal of rocuronium-induced neuromuscular blockade. Rev Bras Anestesiol 2012; 62: 543-7. 